\title{
Government Spending, GDP and Exchange Rate in Zero Lower Bound: Measuring Causality at Multiple Horizons
}

\author{
Charles Olivier Mao Takongmo ${ }^{1}$ (D) $\cdot$ Laetitia Lebihan $^{1}$
}

Published online: 23 July 2020

(c) The Indian Econometric Society 2020

\begin{abstract}
This paper assesses the Granger causality between government spending and gross domestic product (GDP) in the United States at multiple horizons. This paper also analyses the role the real exchange rate plays in the causality measure during the zero lower bound (ZLB) period. Many researchers using theoretical models built in a closed economy suggest that the elasticity between government spending and GDP is very large, when the nominal interest rate is binding. Other researchers, also using theoretical models generally built in an open economy, suggest that the elasticity in the ZLB period is not large. The same conflicting results are reported in the empirical literature mostly using vector auto regressives (VARs), with different restrictions. In this paper, we use a different approach to measure the link between the two variables. The new approach has the advantage of not relying on any restrictions, as is the case with VARs when dealing with causalities. Moreover, our approach is not related to the way the model is built, as is the case with dynamic stochastic general equilibrium (DSGE) types of models. In this paper, we use a Granger causality measure to compare the causality for normal periods with the causality for the ZLB period. We emphasize the role played by the real exchange rate. Our empirical results provide evidence that the causality measures between government spending and GDP are larger and persistent in the ZLB period, but only if the exchange rate is not taken into account. When the exchange rate is taken into account, our measure of causality becomes very small and non-persistent.
\end{abstract}

Keywords Zero lower bound · Government spending

JEL Classification C01 $\cdot$ C32 $\cdot$ E4 $\cdot$ E62 $\cdot$ F41

Charles Olivier Mao Takongmo

maotcharles@gmail.com; maotcharles@yahoo.fr

https://sites.google.com/site/maotakongmocharles/

Laetitia Lebihan

laetitialebihan@yahoo.fr

1 University of Western Ontario, Social Science Center Room 4071, London, ON N6A 5C2,

Canada 


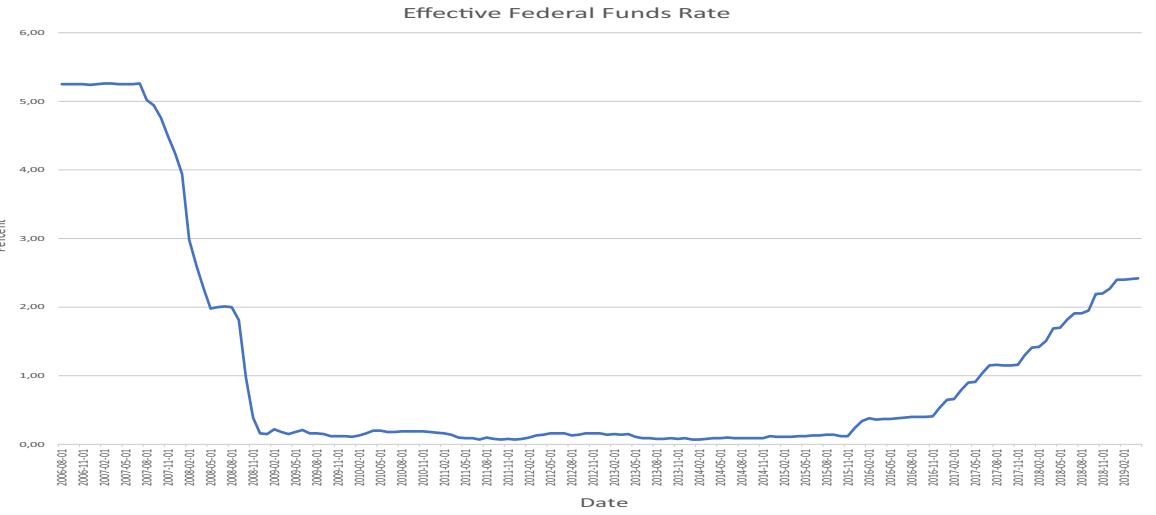

Fig. 1 Effective federal funds rate Source: Graph based on economic data from the Federal Reserve Bank of St. Louis (US). The figure presents the effective federal fund rate from 2006 to 2019.

\section{Introduction}

This paper assesses the Granger causality between government spending and the gross domestic product (GDP) in the United States at multiple horizons. In addition, this paper analyses the effect of the real exchange rate on the causality measure during the zero lower bound (ZLB) period. During the 2007 financial crisis and the recession that followed, the nominal interest rate reached its lower bound and remained at a very low level for a long period. As we can see in Fig. 1, in 2007 the Federal Reserve Bank started to progressively cut the federal fund rate until it reached a very low level, where it remained until 2015. This paper refers to this period of crisis (from 2007 to 2015) as the ZLB period. When the nominal interest rate reached the lowest level, the Federal Reserve Bank lost its monetary policy, which consisted of lowering the nominal interest rate to increase the GDP. The government of the United States then started to increase government spending to grow the GDP.

Many researchers have shown that the elasticity between government spending and the GDP is very large when the nominal interest rate is binding (see for example, Christiano et al. 2011; Woodford 2011). Their results are due to the fact that there is no longer a crowding out effect via the interest rate in a closed economy. In Christiano et al. (2011) the multiplier in their dynamic stochastic general equilibrium (DSGE) model in a closed economy can be close to 4. In a simple new Keynesian model in a closed economy, that can be solved analytically, Woodford (2011) showing that the multiplier is greater than 1 , without specifying the value of the multiplier. The author suggests that the reason for having a multiplier greater than 1 is due to the fact that fiscal expansion causes the real interest rate to fall.

The textbook framework that explains the rule of the exchange rate in the relationship between the government spending and GDP is the Mundell-Fleming model (see Mundell 1963). In a context of perfect capital mobility in a small open economy with flexible exchange rates, the Mundell-Fleming model predicts that increasing 
government spending is ineffective. The model shows that an increase in government spending financed by borrowing creates an excess demand for goods and services, which tends to increase the GDP. This triggers the increase of the demand for money and interest rate increases. Interest rate increases, in turn, attract foreign capital. Exchange is thus appreciated and leads to an equivalent decrease of GDP.

Extensive literature shows that an increase in government spending also appreciates the real exchange rate. Using panel data from 48 industrial countries and emerging markets, Ricci et al. (2013) found that increasing government spending is associated with appreciating real exchange rates. Miyamoto et al. (2019) used panel data on military spending for 125 countries to show that an increase in government purchases triggers a real exchange rate appreciation.

Other researchers have found that the government spending multiplier may not be as large as presented by Christiano et al. (2011), especially for open economies (see for example, Zubairy 2014; Mao Takongmo 2017; Ramey and Zubairy 2018; Miyamoto et al. 2018; Chodorow-Reich 2019). Using US data, Ramey and Zubairy (2018) and Chodorow-Reich (2019) estimated the government spending multiplier in the US to be 1.5 and 1.8, respectively. Using Japan data, Miyamoto et al. (2018) estimated the value to be 1.5. In their DSGE model, Zubairy (2014) obtained a multiplier of 1.07. Using a DSGE model in an open economy, Mao Takongmo (2017) found the government spending multiplier to be 1.03. In Mao Takongmo (2017), the result in an open economy was due to appreciation of the real exchange rate after an increase in government spending. The author called this a crowding-out effect via the exchange rate.

In this paper, we measure the Granger causality during a normal period (1959Q1 to 2006Q4) compared with the same measure during the ZLB period (2007Q1 to 2015Q4). We put more emphasis on the role played by the real exchange rate. Our empirical results provide evidence that the Granger causality measures between government spending and GDP are very high and persistent in the ZLB period, but only if the exchange rate is not taken into account. When the exchange rate is taken into account, our measure of Granger causality between government spending and GDP becomes very small and non-persistent.

Many researchers have empirically compared the link between government spending and the GDP. Using a vector auto regressive (VAR) method and annual panel data from 1951 to 2007 for 62 developed and developing countries, Karras (2012) showed that an increase in trade openness by $10 \%$ of the GDP reduces the fiscal multiplier by $5 \%$. However, this research was done using data from a normal period. Ilzetzkiet al. (2013) used panel data from 1960Q1 to 2007Q4 from 44 developed and developing countries and the structural VAR (SVAR) method to show that fiscal multipliers are usually lower for open economies. Ilzetzkiet al. (2013) also did not cover the ZLB period. Zhang et al. (2016) used the same methodology presented in this paper to measure the causality between exchange rates and commodity prices. To our knowledge, this is the first time the Granger causality measure is used to assess the link between government spending and GDP at multiple horizons. Moreover, we discuss the role played by the real exchange rate.

The impact of government spending on the aggregate production has been one of the main concerns for economists, taxpayers and policymakers. The general 
consensus, summarized by the Rhan curve (see, Mitchell et al. 2005, page 4), suggests that, if government spending is too low, there will be little economic growth because of negative externalities faced by private agents, in the absence of the government, and the lack of infrastructures. On the other hand, when government spending is too high, it will also lead to little growth because of the lack of incentive for the private sector to produce. In the relevant literature, many researchers have found that, in normal periods, government spending is correlated with negative growth (see for example, Ahmed 1986; Fölster and Henrekson 1999; Barro 1991; Lee 1995; Grier and Tullock 1989). As explained by Mitchell et al. (2005), government spending crowds out the private sector; moreover, government decisions are generally less efficient than private decisions. Government spending is also associated with extraction costs.

Some researchers and policymakers have argued that government spending multipliers are larger in difficult economic conditions (e.g., period of slack, financial crisis, and recently the coronavirus crisis [COVID-19]). For example, Auerbach and Gorodnichenko (2012), using US data and cross-country data, found that the multiplier was close to zero during expansions and about 1.5 during recessions. Gordon and Krenn (2010) also obtained a larger multiplier before 1941 compared to that after 1941, using United States data from 1919 to 1953.

Even in periods of severe slack, some researchers have reported a very small government spending multiplier. For example, Crafts and Mills (2013) used data from the UK from 1922 to 1938 and obtained multipliers less than 0.8. Note that 1922-1938 is known as a period of extreme slack. Owyang et al. (2013) did not find any difference in terms of the value of multipliers when comparing periods of slack with normal periods using newly constructed historical US data.

Researchers usually measure the link between government spending and GDP using VARs models. In that case, authors usually assume some restrictions in order to identify the government spending shock, that will make the interpretation of their estimator causal. They then compute the effect of that shock to the GDP. There are many restrictions in the literature. Each restriction leads to a different estimator. In the causality measure used in this paper, we do not have to use those restrictions. The method of this paper also provides a different way to assess the impact of government spending on DGP.

Compared to the existing empirical literature that mostly uses controversial restrictions in the VARs in order to identify the effect of government spending shocks ${ }^{1}$, we use the Granger strategy to measure the causality between government spending and GDP. We contribute to the literature by comparing the measures of causality between government spending and GDP during the ZLB period versus that during the normal period. Our second contribution is to assess the role of the exchange rate on the measure of the causal link between government spending and the GDP in the ZLB period compared to that in normal periods. Additional tests of comparison are also presented in the paper.

\footnotetext{
${ }^{1}$ Note that each restriction method in the VARs leads to its own results.
} 
The paper is organized as follows: "The Framework" presents the theoretical framework. "Empirical Analysis" presents the data used and the results. "Conclusion" concludes the paper.

\section{The Framework}

A time series $\{X(t)\}$ causes another time series $\{Y(t)\}$, in the sense of Wiener (1956) and Granger (1969), if it is possible to better predict $\{Y(t)\}$ using all available information rather than using all available information without $\{X(t)\}$. Following Dufour and Renault (1998), we define the concept of non-causality in terms of orthogonality conditions between sub-spaces of a Hilbert space of random variables with finite second moments.

Let $L^{2} \equiv L^{2}(\Omega, \mathcal{A}, Q)$ represent a Hilbert space of real random variables with finite second moments and mean zero, defined on a common probability space $(\Omega, \mathcal{A}, Q)$ with covariance as the inner product. As defined by Dufour and Renault (1998), the information available at time $t \subseteq \mathbb{Z}$ is a closed Hilbert subspace $I(t) \subseteq L^{2}$. The set of integers is denoted by $\mathbb{Z}$. We consider a set of non-decreasing sequences of information $I$ with a starting point $\omega \in \mathbb{Z} \cup\{-\infty\}$. That information set $I$ can be written as:

$$
I=\{I(t): t \in \mathbb{Z}, t>\omega\} \text { with } t<t^{\prime} \Rightarrow I(t) \subseteq I\left(t^{\prime}\right) \text { for all } t>\omega,
$$

where $I(t)$ is a Hilbert subspace of $L^{2}, \omega \in \mathbb{Z} \cup\{-\infty\}$ represents a "starting point," and $\mathbb{Z}$ is the set of integers. Using the notation of Dufour and Renault (1998), $X(\omega, t]$ and $Y(\omega, t]$ are information contained, respectively, in the variables $X$ and $Y$ up to time $t$. The information is added as follows:

$$
\begin{gathered}
I_{X}(t)=I(t)+X(\omega, t], \\
I_{X Y}(t)=I(t)+X(\omega, t]+Y(\omega, t]=I_{X}(t)+Y(\omega, t] .
\end{gathered}
$$

$I_{X}(t)$ is information obtained by adding $X(\omega, t]$ to $I(t)$, and $I_{X Y}(t)$ is the information obtained by adding $Y(\omega, t]$ to $I_{X}(t)$. For horizon $h>0, P[X(t+h) \mid B(t)]$ is the best forecast of $X(t+h)$ based on the information set $B(t)$, with $U[X(t+h) \mid B(t)]=X(t+h)-P[X(t+h) \mid B(t)]$, the forecasting error. The variance-covariance matrix of the forecasting error is:

$$
\Sigma[X(t+h) \mid B(t)]=\mathrm{E}\left\{U[X(t+h) \mid B(t)] U\left[X(t+h) \mid B_{t}\right]^{\prime}\right\} .
$$

\section{Causality Measures}

Causalities may exist from $\mathrm{X}$ to $\mathrm{Y}$ or from $\mathrm{Y}$ to $\mathrm{X}$. As Dufour and Taamouti (2010) pointed out, a statistical test cannot achieve that goal as it is only informative of the existence or non-existence of causality and statistical significance usually depends on available data and power. As McCloskey and Ziliak (1996) 
and Dufour and Taamouti (2010) argued, at a given level, a large effect may not be statistically significant and a statistically significant effect may not be relevant from an economic point of view. This is why the magnitude of forecasting improvement based on a loss function is preferred.

The causality measures proposed in Dufour and Taamouti (2010) for horizon $h>0$ are based on the ratio of the restricted and unrestricted forecasting error. These causality measures are non-negative, cancel only when the causality does not exist, and increase with the strength of the causality. Definition 4.1 in Dufour and Taamouti (2010) defines the causality measure as follows.

\section{Definition (Causality Measures at Horizon h).}

The function

$$
C(Y \stackrel{h}{\longrightarrow} X \mid I)=\ln \left[\frac{\operatorname{det} \Sigma\left[X(t+h) \mid I_{X}(t)\right]}{\operatorname{det} \Sigma\left[X(t+h) \mid I_{X Y}(t)\right]}\right]
$$

defines the causality measure at horizon $h$ from $Y$ to $X$, given $I$. Similarly, the function

$$
C(X \stackrel{h}{\longrightarrow} Y \mid I)=\ln \left[\frac{\operatorname{det} \Sigma\left[Y(t+h) \mid I_{Y}(t)\right]}{\operatorname{det} \Sigma\left[Y(t+h) \mid I_{X Y}(t)\right]}\right]
$$

defines the causality measure from $X$ to $Y$ at horizon h given $I$.

$C(Y \stackrel{h}{\longrightarrow} X \mid I)$ (resp. $C(X \stackrel{h}{\longrightarrow} Y \mid I))$ measures the degree of the causal effect from $Y$ to $X$ (resp. $X$ to $Y$ ) given $I$ and the past of $Y$ (resp. $X$ ).

$C(Y \stackrel{h}{\longrightarrow} X \mid I)$ measure the causal effect from $\mathrm{Y}$ to $\mathrm{X}_{h}$ at horizon $\mathrm{h}$, given $\mathrm{I}$ and the past of $\mathrm{X}$ (see, Dufour and Taamouti 2010). $C(Y \stackrel{h}{\longrightarrow} X \mid I)$ is also a measure of the reduction of the variance of the forecast error of $X(t+h)$ when taking into account the past of Y, given information I (Geweke 1982). Lastly, $C(Y \stackrel{h}{\longrightarrow} X \mid I)$ represent the amount of information from the past of $\mathrm{Y}$ which improves the forecast of $X(t+h)$, given I (see Dufour and Taamouti 2010; Geweke 1982).

\section{Causality Measure Based on VARMA Models in Terms of Impulse Response Functions}

Consider three second-order stationary time series variables: $X(t), Y(t)$, and $S(t)$. Let $W(t)=\left(X(t)^{\prime}, Y(t)^{\prime}, S(t)^{\prime}\right)^{\prime} \in L^{2}$. Assume that $W(t)$ has the following VARMA $(\mathrm{p}, \mathrm{q})$ representation:

$$
\Phi(L) W(t)=\Theta(L) u(t)
$$

where, 


$$
\begin{aligned}
& \Phi(L)=\left(\begin{array}{lll}
\varphi_{X X}(L) & \varphi_{X Y}(L) & \varphi_{X S}(L) \\
\varphi_{Y X}(L) & \varphi_{Y Y}(L) & \varphi_{Y S}(L) \\
\varphi_{S X}(L) & \varphi_{S Y}(L) & \varphi_{S S}(L)
\end{array}\right) ; \quad \Theta(L)=\left(\begin{array}{ccc}
\theta_{X X}(L) & \theta_{X Y}(L) & \theta_{X S}(L) \\
\theta_{Y X}(L) & \theta_{Y Y}(L) & \theta_{Y S}(L) \\
\theta_{S X}(L) & \theta_{S Y}(L) & \theta_{S S}(L)
\end{array}\right) \\
& \varphi_{l l}(L)=1-\sum_{i=1}^{p} \varphi_{l l i} L^{i}, \quad \varphi_{l k}(L)=\sum_{i=1}^{p} \varphi_{l k i} L^{i} \\
& \theta_{l l}(L)=1-\sum_{j=1}^{q} \theta_{l l j} L^{j}, \quad \theta_{l k}(L)=\sum_{i=1}^{q} \theta_{l k j} L^{j},
\end{aligned}
$$

for $l \neq k$ and $l, k=X, Y, S$,

$$
E[u(t)]=0, E\left[u(t) u(s)^{\prime}\right]=\left\{\begin{array}{cc}
\Sigma_{u} & \text { for } \mathrm{s}=\mathrm{t} \\
0 & \text { for } \mathrm{s} \neq \mathrm{t}
\end{array}\right.
$$

$\Sigma_{u}$ is a symmetric positive definite matrix and $\mathrm{u}(\mathrm{t})$ is assumed to be orthogonal to $\{W(s), s<t\}$. If the process $W(t)$ is stationary, it has a $M A(\infty)$ representation, which can been written as follows:

$$
\begin{gathered}
W(t)=\Psi(L) u(t), \\
\Psi(L)=\Phi(L)^{-1} \Theta(L)=\sum_{j=0}^{\infty} \Psi_{j} L^{j}=\sum_{j=0}^{\infty}\left(\begin{array}{lll}
\Psi_{X X j}(L) & \Psi_{X Y j}(L) & \Psi_{X S j}(L) \\
\Psi_{Y X j}(L) & \Psi_{Y Y j}(L) & \Psi_{Y S j}(L) \\
\Psi_{S X j}(L) & \Psi_{S Y j}(L) & \Psi_{S S j}(L)
\end{array}\right)
\end{gathered}
$$

where $\Psi_{0}=I_{3}$.

A vector moving average, $\operatorname{VMAR}(\infty)$, representation of the unconstrained model is written as

$$
W(t+h)=\Psi(L) u(t+h)=\sum_{j=0}^{\infty} \Psi_{j} L^{j} u(t+h)
$$

and the forecasting error of $W(t+h)$ is

$$
\begin{aligned}
U\left(W(t+h) \mid I_{W}(t)\right) & =W(t+h)-E\left[W\left((t+h) \mid I_{W}(t)\right)\right] \\
& =\sum_{j=0}^{h-1} \Psi_{j} u(t+h-j) .
\end{aligned}
$$

The covariance matrix of $W(t+h)$ is

$$
\Sigma\left[W(t+h) \mid I_{W}(t)\right]=\sum_{j=0}^{h-1} \Psi_{j} \Sigma_{u} \Psi_{j}^{\prime}
$$

The variance-covariance matrix of the unconstrained forecast error of $X(t+h)$ is 


$$
\Sigma\left[X(t+h) \mid I_{W}(t)\right]=\sum_{j=0}^{h-1} J_{1} \Psi_{j} \Sigma_{u} \Psi_{j}^{\prime} J_{1}^{\prime}
$$

and the variance-covariance matrix of the unconstrained forecast error of $Y(t+h)$ is

$$
\Sigma\left[Y(t+h) \mid I_{W}(t)\right]=\sum_{j=0}^{h-1} J_{2} \Psi_{j} \Sigma_{u} \Psi_{j}^{\prime} J_{2}^{\prime}
$$

where $J_{1}=(1,0,0)$ and $J_{2}=(0,1,0)$.

Similarly, the constrained model is

$$
W_{0}(t)=\sum_{i=0}^{\infty} \bar{\Psi}_{j} L^{j} \epsilon(t)
$$

where $\epsilon$ and $\bar{\Psi}$ represent the structural errors and the parameters in the restricted models, respectively. The forecasting error of the constrained model $W_{0}(t+h)$ is

$$
\begin{aligned}
U_{0}\left(W_{0}(t+h) \mid I_{W_{0}}(t)\right) & =W_{0}(t+h)-E\left[W_{0}\left((t+h) \mid I_{W_{0}}(t)\right)\right] \\
& =\sum_{j=0}^{h-1} \bar{\Psi}_{j} \epsilon(t+h-j)
\end{aligned}
$$

and its variance-covariance is

$$
\Sigma\left[W_{0}(t+h) \mid I_{W_{0}}(t)\right]=\sum_{j=0}^{h-1} \bar{\Psi}_{j} \Sigma_{\epsilon} \bar{\Psi}_{j}^{\prime}
$$

The variance-covariance of the constrained forecast error of $X(t+h)$ is

$$
\Sigma\left[X(t+h) \mid I_{W_{0}}(t)\right]=\sum_{j=0}^{h-1} J_{0} \bar{\Psi}_{j} \Sigma_{\epsilon} \bar{\Psi}_{j}^{\prime} J_{0}
$$

with $J_{0}=(1,0)$.

Under a VARMA representation in (6) and invertibility, Theorem 5.1 in Dufour and Taamouti (2010) shows that the causality measure from $\mathrm{Y}$ to $\mathrm{X}$ at horizon $h \geq 1$, in terms of reduced-form impulse responses, is:

$$
C(Y \stackrel{h}{\longrightarrow} X \mid I)=\ln \left[\frac{\operatorname{det}\left(\sum_{j=0}^{h-1} J_{0} \bar{\Psi}_{j} \Sigma_{\epsilon} \bar{\Psi}_{j}^{\prime} J_{0}\right)}{\operatorname{det}\left(\sum_{j=0}^{h-1} J_{1} \Psi_{j} \Sigma_{u} \Psi_{j}^{\prime} J_{1}^{\prime}\right)}\right]
$$

with $J_{1}=(1,0,0)$ and $J_{0}=(1,0)$.

If $S$ is not taken into account in the measure, Eq. (9) is a measure of unconditional causality from $Y$ to $X$. 


\section{Estimation and Inference}

Assume that for each variable we have $T$ observations. Also assume that our $\operatorname{ARMA}(p, q)$ model is equivalent to a $\operatorname{VAR}$ model with infinite order, $\Phi(L) W(t)=u(t)$, that can be approximated by a $V A R$ representation with finite order. The order $k(T)$ may depend on the sample size. The finite order VAR representation can be written as

$$
\Phi_{k}(L) W(t)=u(t)
$$

The order of the process is chosen using the Akaike information criteria (AIC). The ordinary least squares (OLS) estimators of unknown parameters of the $\operatorname{VAR}[k(T)]$ model are estimated. These estimates are used to compute the impulse response estimators $\hat{\Psi}_{k}$ of the unrestricted model. The same methodology is used in the estimation of the impulse response estimators of the restricted model $\bar{\Psi}_{k}$. The OLS estimators of the variance-covariance matrix of the forecasting error of the unrestricted model $\widehat{\Sigma}_{u, k}$ and restricted model $\widehat{\Sigma}_{\epsilon, k}$ are used as estimators of a corresponding unknown variance-covariance matrix of forecasting errors. These estimators replace the unknown parameters in the causality measure to obtain an estimator of the causality measure.

An estimator of the causality measure from $\mathrm{Y}$ to $\mathrm{X}$ at horizon $h \geq 1$, in terms of reduced-form impulse responses, is:

$$
\widehat{C}(Y \stackrel{h}{\longrightarrow} X \mid I)=\ln \left[\frac{\operatorname{det}\left(\sum_{j=0}^{h-1} J_{0} \hat{\bar{\Psi}}_{j, k} \widehat{\Sigma}_{\epsilon, k} \hat{\bar{\Psi}}_{j k}^{\prime} J_{0}\right)}{\operatorname{det}\left(\sum_{j=0}^{h-1} J_{1} \hat{\Psi}_{j, k} \hat{\Sigma}_{u, k} \hat{\Psi}_{j k}^{\prime} J_{1}^{\prime}\right)}\right]
$$

with $J_{1}=(1,0,0)$ and $J_{0}=(1,0)$.

Proposition 8.1 of Dufour and Taamouti (2010) shows that, under some regularity conditions,

$$
\sqrt{T}[\widehat{C}(X \stackrel{h}{\longrightarrow} Y \mid I)-C(X \stackrel{h}{\longrightarrow} Y \mid I)] \stackrel{d}{\longrightarrow} N\left(0, \Sigma_{c}(h)\right)
$$

where

$$
\Sigma_{c}(h)=\frac{\partial C(X \stackrel{h}{\longrightarrow} Y \mid I)}{\partial \delta} \Sigma_{\delta} \frac{\partial C(X \stackrel{h}{\longrightarrow} Y \mid I)^{\prime}}{\partial \delta}
$$

$\delta=\left[\operatorname{vec}(\Phi)^{\prime}, \operatorname{vech}\left(\Sigma_{u}\right)^{\prime}\right]$ and $\Sigma_{\delta}$ is the asymptotic variance-covariance matrix of $\widehat{\delta}$.

\section{Bootstrap}

The bootstrap method to build confident intervals was proposed by Dufour and Taamouti (2010). 
1. Let $W=\left(X^{\prime}, Y^{\prime}, S^{\prime}\right)^{\prime}$. Estimate the $\operatorname{VAR}(p)$ model, $W(t+h)=\Phi(L) W(t)+\epsilon(t+h)$ and save the OLS estimator of the parameters $\widehat{\Phi}(L)$ and the residual $\widehat{\epsilon}(t+h)$. Let $\left\{\epsilon^{*}(t)=\left(\epsilon_{1}^{*}(t+h), \ldots \epsilon_{N}^{*}(t+h)\right)\right\}$ denote the bootstrap sample from $\{\widehat{\epsilon}(t+h)=W(t+h)-\widehat{\Phi}(L) W(t)\}$

2. . Generate the bootstrap panel data using the following bootstrap data-generating process:

$$
W^{*}(t+h)=\widehat{\Phi}(L) W(t)+\epsilon^{*}(t+h)
$$

3. Estimate the $\operatorname{VAR}(p)$ model, $W^{*}(t+h)=\Phi(L)^{*} W^{*}(t)+\xi(t+h)$, and save the bootstrap OLS estimator $\widetilde{\Phi}^{*}(L)$ and bootstrap residual $\widetilde{\epsilon}^{*}(t+h)$.

4. Let $W_{0}=\left(X^{\prime}, S^{\prime}\right)^{\prime}$. Estimate the constrained model, $W_{0}^{*}(t+h)=\Phi_{0}(L)^{*} W_{0}^{*}(t)+\epsilon^{*}(t+h)$ using the bootstrap sample $W^{*}$.

5. Calculate, at step $j$, the bootstrap causality measures at horizon $\mathrm{h}$, denoted by $\widetilde{C}^{(j) *}(X \stackrel{h}{\longrightarrow} Y \mid I)$

6. Repeat steps 2 through $5 B$ times, and save the bootstrap distribution of the measure of causality.

Proposition 8.2 from Dufour and Taamouti (2010) shows that, under some regularity conditions,

$$
\sqrt{T}\left[\widetilde{C}^{*}(X \stackrel{h}{\longrightarrow} Y \mid I)-\widehat{C}(X \stackrel{h}{\longrightarrow} Y \mid I)\right] \stackrel{d}{\longrightarrow} N\left(0, \Sigma_{c}(h)\right)
$$

where $\Sigma_{c}(h)$ is defined in the previous subsection.

\section{Empirical Analysis}

\section{Data}

Our main objective is to assess empirically the causality measure between government spending and real GDP in the case of ZLB and analyse that causality measure when the exchange rate is taken into account. The data are quarterly observations from 1959Q1 through 2015Q4 United States macroeconomic time series from McCracken and Ng (2016). This is an updated version of Stock and Watson (2012). The main source of data is the database of the Federal Reserve Bank of St. Louis. Outliers have been removed, and the series have been transformed by the authors to induce stationarity. We use data from the panel data created by those authors to facilitate the replication of this paper. The US real GDP is expressed in billions of chained 2009 dollars, as is the real government consumption. We also use the exchange rate between Canada and the United States. All three times series have been transformed by the authors by applying the first difference of the log in the original data. 

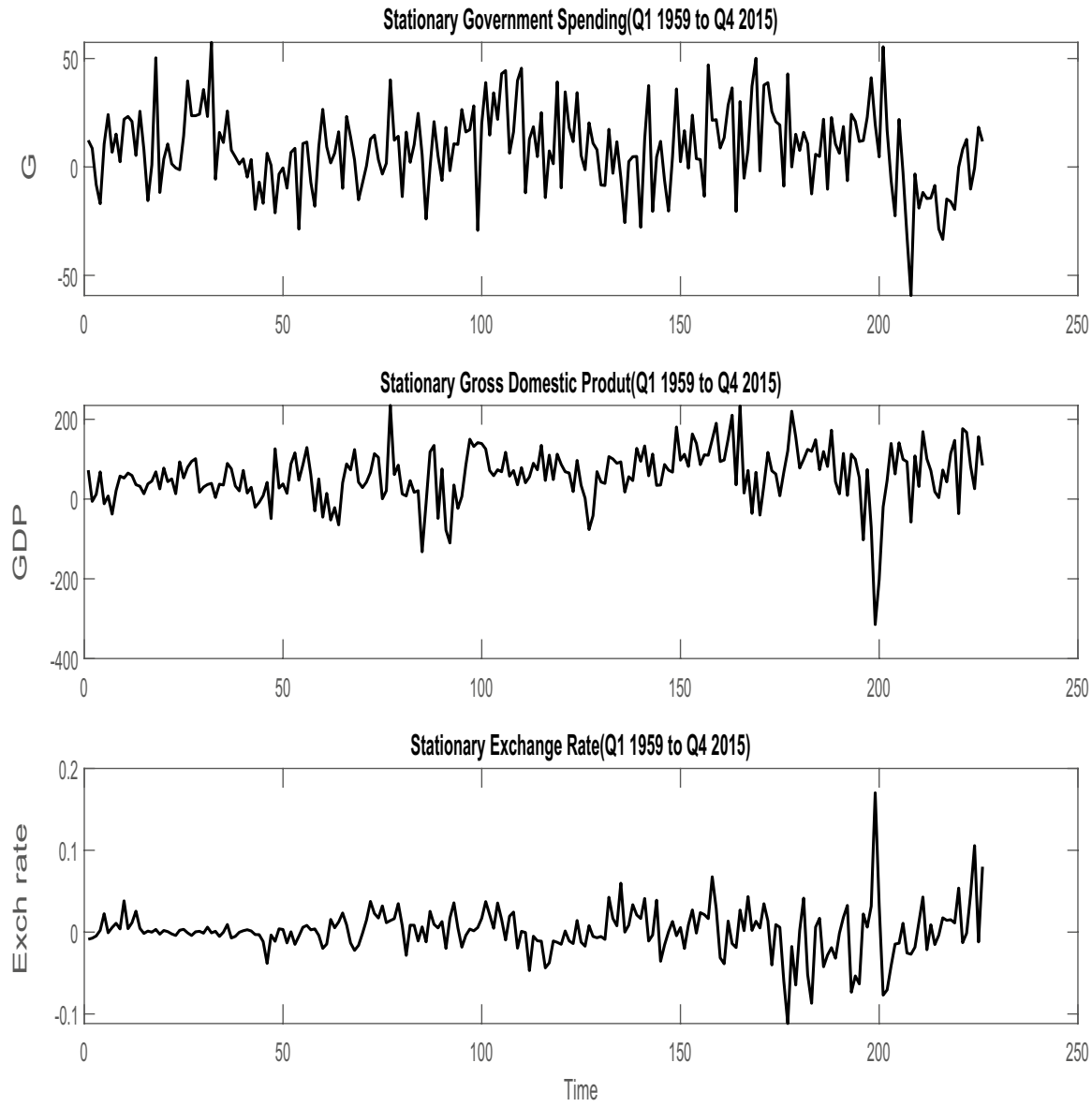

Fig. 2 Data. This graph represents government spending, gross domestic product, and exchange rate, transformed to induce stationary variables. Data span from Q1 1959 to Q4 2015

It is well known that, when univariate processes contain a unit root, the asymptotic distribution and rate of convergence of estimators are different than for stationary variables (Hamilton 1994, page 475). In fact, the asymptotic distribution of the estimators is functional of Brownian motion. We plot the data used in this paper in Fig. 2. We also verify that the variables are stationary.

\section{Coefficient Stability at the Break Point 2007Q1}

We use the Chow (1960) test to assess the possibility of structural change during the ZLB period compared to the normal periods. The explanatory variables are government spending and exchange rate, and the dependent variable is the GDP. The break point chosen is the beginning of the crisis, i.e., 2007Q1. The result of the test presented in Table 1 suggests that we can reject the null hypothesis of the stability 
Table 1 Chow test

\begin{tabular}{lc}
\hline Stat & p-value \\
\hline Chow test & \\
5.649 & 0.000
\end{tabular}

Test is for stability of coefficients of $\theta$ in a multiple linear regression model $y=X \theta+\varepsilon$. Data are split at the break points 2007Q1

Table 2 Unit root test

\begin{tabular}{|c|c|c|c|c|c|c|c|c|}
\hline \multirow[t]{3}{*}{ Variables } & \multicolumn{4}{|c|}{ ADF test } & \multicolumn{4}{|l|}{ PP } \\
\hline & \multicolumn{2}{|c|}{ t Statistic } & \multicolumn{2}{|c|}{ Lag adj t statistic } & \multicolumn{2}{|c|}{ t Statistic } & \multicolumn{2}{|c|}{ Lag adj t statistic } \\
\hline & Stat & p-value & Stat & p-value & Stat & p-value & Stat & p-value \\
\hline Government spending & -5.71 & 0.001 & -77.97 & 0.001 & -12.12 & 0.001 & -180.3 & 0.001 \\
\hline GDP & -6.26 & 0.001 & -97.13 & 0.001 & -10.02 & 0.001 & -140.8 & 0.001 \\
\hline Exchange rate & -6.54 & 0.001 & -122.0 & 0.001 & -10.66 & 0.001 & -152.4 & 0.001 \\
\hline
\end{tabular}

The "t statistic" is the standard t statistic, "Lag adj t statistic" is the lag-adjusted, unstudentized t statistic

of the coefficients at the $1 \%$ confidence level (i.e., there is a significant structural change when comparing the normal periods to the ZLB period).

\section{Unit Root Tests}

We perform the Phillip-Perron (PP) test and the augmented Dickey-Fuller (ADF) tests. The Phillip-Perron test adjusts the statistics for the serial correlation of data in difference. The Dickey-Fuller tests adds the lags of difference data to the auto-regression.

For the Phillips-Perron unit-root tests, the null hypothesis and the alternative are:

$$
\begin{aligned}
H_{0} & : x_{t}=x_{t-1}+e_{t} \\
H_{1} & : x_{t}=c+b x_{t-1}+e_{t} \\
& \text { with } \operatorname{AR}(1) \text { coefficient } \mathrm{b}<1 .
\end{aligned}
$$

The null hypothesis and the alternative for the Dickey-Fuller test are:

$$
\begin{aligned}
H_{0} & : x_{t}=x_{t-1}+\beta_{1} \triangle x_{t-1}+\beta_{2} \triangle x_{t-2}+\cdots+\beta_{p} \triangle x_{t-p}+\epsilon_{t} \\
H_{1} & : x_{t}=c+\phi x_{t-1}+\beta_{1} \triangle x_{t-1}+\beta_{2} \triangle x_{t-2}+\cdots+\beta_{p} \triangle x_{t-p}+\epsilon_{t} \\
& \text { with AR(1) coefficient } \phi<1 .
\end{aligned}
$$

Table 2 presents the results obtained for the two tests. As we can see from the table, each test rejects the null hypothesis of non-stationarity at the $1 \%$ confidence level.

For simplicity, let $G$ define the stationary transformation of real government spending, GDP the stationary transformation of real GDP, and $S$ the stationary transformation of exchange rate. In our VAR representation in (10), 
$W(t)=\left(G D P(t)^{\prime}, G(t)^{\prime}, S(t)^{\prime}\right)^{\prime}$ for conditional causality, and $W(t)=\left(G D P(t)^{\prime}, G(t)^{\prime}\right)^{\prime}$ for unconditional causality. The value $k$ that represents the order of the VAR is chosen using $A I C$ information criteria.

\section{Empirical Results}

This section presents the estimated conditionals and unconditional causality measures between the variables of interest for ZLB periods and the normal period. This section also presents the results for test statistics that compare the obtained causality measures.

\section{Conditional Causality Versus Unconditional Causality Between Government Spending and GDP in the ZLB Period}

Figure 3 presents the unconditional and conditional causalities between government spending and GDP in ZLB. In ZLB, we observe that, when the exchange rate is taken into account (see panels c and d of Fig. 3), the causality measures between government spending and GDP are lower than the causality when the exchange rate is not taken into account (see panels a and b). In addition, the causality lasts less time (no longer than $\mathrm{h}=1$ period ahead when the bootstrap confidence's lower value starts to take the value of zero). This suggests that the exchange rate may be a channel that reduces the causality between government spending and gross domestic product.

To test for stochastic inequality between the sets of causality measures, we also report the p-values of both the Wilcoxon signed-rank test ${ }^{2}$ and the Welch test. ${ }^{3}$

The second column of Table 3 presents the result for the tests comparing the conditional causality and the unconditional causality from government spending to GDP in ZLB periods. The p-values reported for the Wilcoxon rank test $(0.00)$ and Welch test $(0.04)$ are both less than 5\%. This suggests that we can reject the null hypothesis that the population's conditional causality and the population's unconditional causality are the same in the ZLB period at the 5\% confidence level.

\section{Conditional Causality Versus Unconditional Causality Between Government Spending and GDP in Normal Periods}

Figure 4 presents the unconditional and conditional causalities between government spending and GDP in normal periods. Even in normal periods, we observe that the conditional causalities between government spending and GDP are lower than the conditional causalities. The exchange rate may thus be a channel that reduces the causality between government spending and gross domestic product. However, in

\footnotetext{
2 Wilcoxon (1945) and Fay and Proschan (2010).

3 The null hypothesis stipulates that the two data sets come from the same distribution (Fay and Proschan 2010).
} 

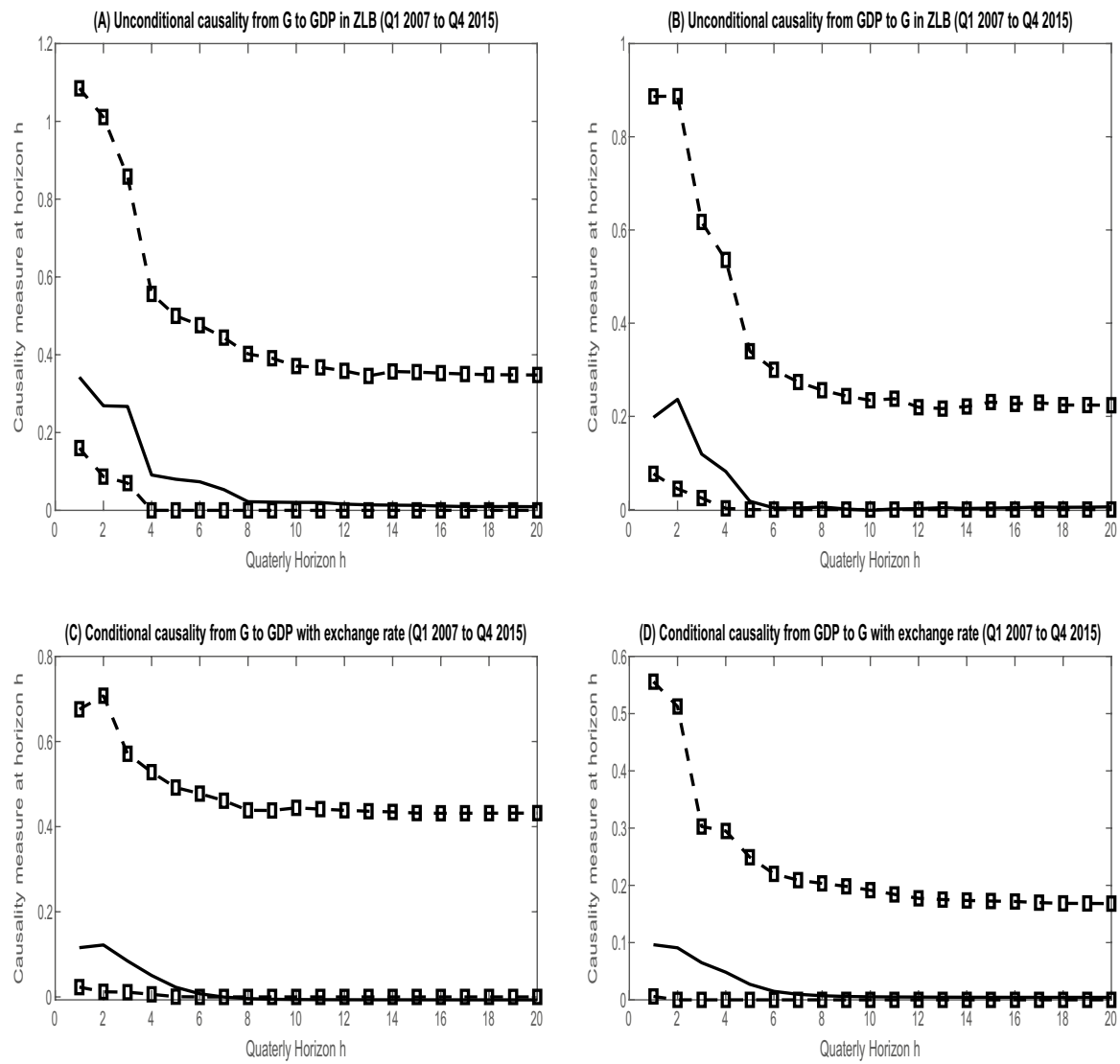

- D- $95 \%$ Percentile boostrap interval $\longrightarrow$ OLS causality estimate $-\mathbf{D}-$

- $\mathbf{0}$ - $95 \%$ Percentle boostrap interval $\longrightarrow$ OLS causality estimate $-\boldsymbol{D}-$

Fig. 3 Unconditional (a, b) and conditional (c, d) causality measures between government spending and real gross domestic product in ZLB period (Q1 2007 to Q4 2015). Note: This figure presents the unconditional and conditional causalities between government spending and the exchange rate during the ZLB period. The unconditional causalities $\mathbf{a}, \mathbf{b}$ are measured without taking into account the real exchange rate whereas the conditional causalities c, $\mathbf{d}$ take into account the real exchange rate. A presents the unconditional causality from G to GDP while b presents the unconditional causality from GDP to G. c represents the conditional causality from G to GDP, and $\mathbf{d}$ represents the conditional causality from GDP to G. In ZLB, the causality measures are lower when the exchange rate is taken into account than when the exchange rate is not taken into account (see $\mathbf{a}, \mathbf{b}$ ). In addition, the causality lasts less time (no longer than $h=1$ period ahead when the bootstrap confidence's lower value starts to take the value of zero). Data used in this graph span from Q1-2007 to Q4-2015. The model for the unconditional causalities is $W(t)=\Phi_{0, k}+\sum_{i=1}^{k} \Phi_{i, k} W(t-i)+u(t)$ with $W(t)=\left(G D P(t)^{\prime}, G(t)^{\prime}\right)^{\prime}$. The model for the conditional causality is $W(t)=\Phi_{0, k}+\sum_{i=1}^{k} \Phi_{i, k} W(t-i)+u(t)$ with $W(t)=\left(G D P(t)^{\prime}, G(t)^{\prime}, S(t)^{\prime}\right)^{\prime}$

normal periods the differences between the conditional causalities and unconditional causalities do not seem to be substantial.

The last column of Table 3 presents the results of the tests comparing the conditional causality and unconditional causality from government spending to GDP in normal periods. The p-values reported for the Wilcoxon rank test (0.07) and Welch 

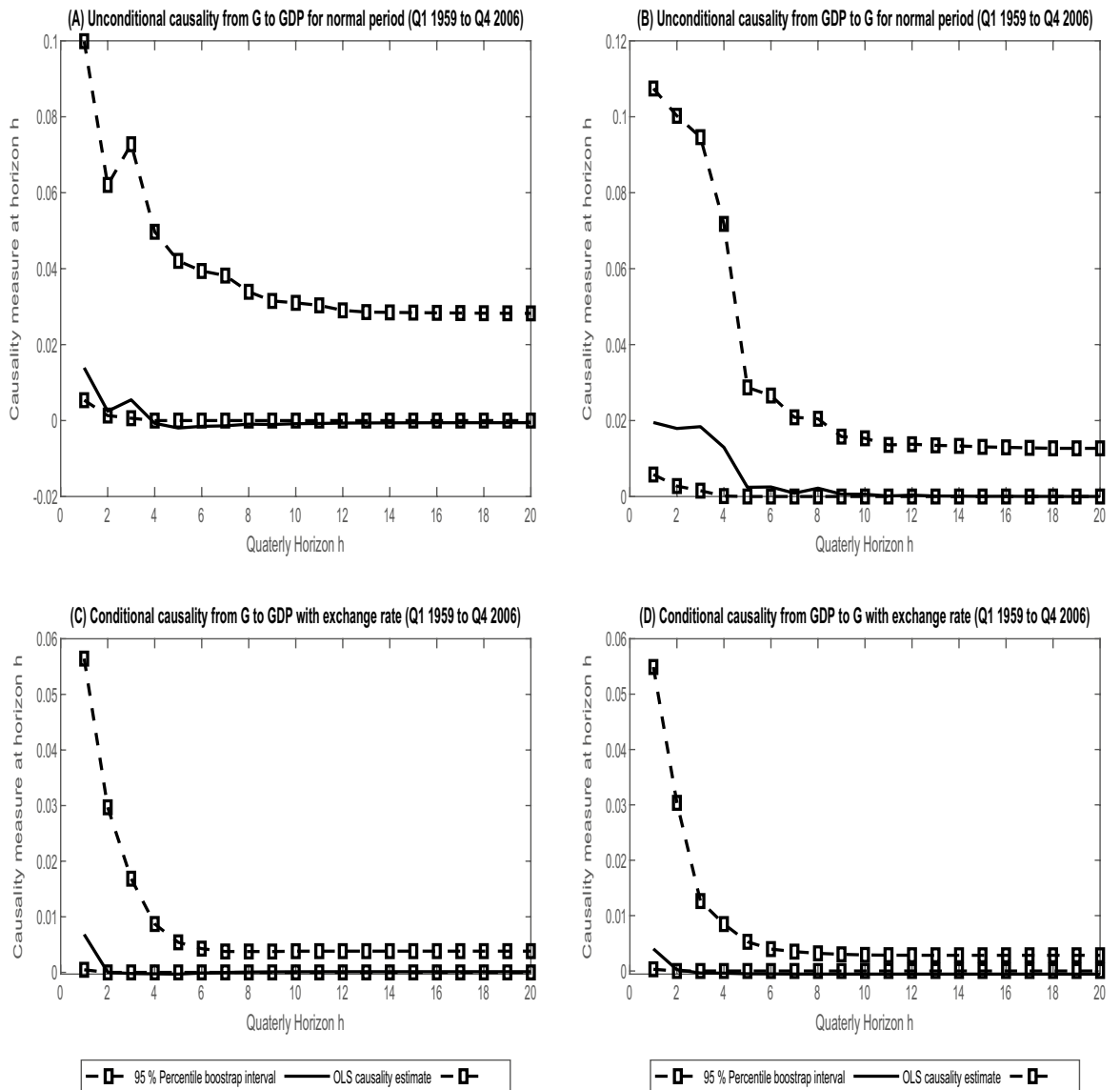

Fig. 4 Unconditional (a, b) and conditional (c, d) causality measures between government spending and real gross domestic product in normal periods (Q1 1959 to Q4 2006). Note: This figure presents the unconditional and conditional causalities between the government spending and the exchange rate during normal periods. The unconditional causalities $\mathbf{a}, \mathbf{b}$ are measured without taking into account the real exchange rate whereas the conditional causalities $\mathbf{c}, \mathbf{d}$ take into account the real exchange rate. a Presents the unconditional causality from G to GDP; b indicates the unconditional causality from GDP to G. c Represents the conditional causality from G to GDP, and $\mathbf{d}$ shows the conditional causality from GDP to G. Both the conditional and unconditional causalities are lower in normal periods than in ZLB periods. Moreover, as shown in this graph, the conditional causality is lower and lasts less than the unconditional causality

Table 3 Comparing unconditional causality from $\mathrm{G}$ to GDP and the corresponding conditional causality

\begin{tabular}{lcc}
\hline & ZLB period & Normal periods \\
\hline Tests comparing conditional versus unconditional causalities \\
p-value of the Wilcoxon test & 0.0000 & 0.0731 \\
p-value of the Welch test & 0.0425 & 0.9947 \\
\hline
\end{tabular}

This table shows results obtained for the Wilcoxon rank test and Welch test that compare the unconditional causality from G to GDP and the corresponding conditional causality. The p-values for these tests are reported for the ZLB and normal periods 
Table 4 Comparing causalities from $\mathrm{G}$ to GDP in ZLB versus normal periods

\begin{tabular}{lcc}
\hline & Unconditional & Conditional \\
\hline Tests: causality from G to GDP in & ZLB versus normal periods \\
p-value of the Wilcoxon test & 0.0000 & 1.0000 \\
p-value of the Welch test & 0.0073 & 0.1154 \\
\hline
\end{tabular}

This table shows results obtained for the Wilcoxon rank test and Welch test that compare, in the second column, the unconditional causality in ZLB versus the unconditional causality in normal periods, from G to GDP. The table also compares, in the last column, the conditional causality in ZLB versus the conditional causality in normal periods, again from G to GDP. The p-values for these tests are reported

test (0.99) are both greater than 5\%. This suggests that we cannot reject the null hypothesis that the population's conditional causality and the population's unconditional causality are the same in normal periods at the 5\% confidence level.

\section{Unconditional Causality in ZLB Versus Unconditional Causality in Normal Periods, Between Government Spending and GDP}

Panel a of Fig. 3 presents the unconditional causality from government spending to GDP in ZLB. Panel a of Fig. 4 presents the same measure in normal periods. We observe that the unconditional causality in ZLB is very large compared to normal periods. The unconditional causality is also more persistent in the ZLB period. To test for stochastic inequality between the sets of unconditional causality measures (ZLB versus normal), we also report the p-values of both the Wilcoxon signed-rank test and Welch test.

The second column of Table 4 presents the result for the tests of difference between unconditional causality in the ZLB period and normal periods (from government spending to GDP). The two p-values reported for the Wilcoxon rank test $(0.000)$ and Welch test $(0.007)$ are both less than $1 \%$. This suggests that we can reject the null hypothesis that the population's unconditional causality in ZLB versus normal periods is the same at the $1 \%$ confidence level.

\section{Conditional Causality in ZLB Versus Conditional Causality in Normal Periods, Between Government Spending and GDP}

Panel c of Fig. 3 presents the conditional causality from government spending to GDP in ZLB. Panel c of Fig. 4 presents the same measure in normal periods. We observe that the conditional causality in ZLB is a little bit greater than in normal periods. The difference is not substantial. The conditional causality is also a little bit more persistent in the ZLB period.

The last column of Table 4 presents the result for the tests comparing the conditional causality from government spending to GDP in ZLB periods, with the corresponding conditional causality in normal periods. The p-values reported for the Wilcoxon rank test (1.00) and Welch test (0.115) are both larger than 5\%. This suggests 
that we cannot reject the null hypothesis that the population's conditional causality in ZLB and the population's conditional causality in normal periods are the same at the $5 \%$ confidence level.

\section{Discussion}

\section{Comparing the Results with those from the Theoretical Literature}

This paper shows empirically that the measure of causality from government spending to GDP is significantly larger in the ZLB period than the normal period when the exchange rate is not taken into account (unconditional causality). However, the causality measure is not significantly larger in the ZLB period than in the normal period when the exchange rate is taken into account (conditional causality). These results are consistent with those obtained by Christiano et al. (2011) as well as Mao Takongmo (2017) using DSGE models. ${ }^{4}$ In their respective theoretical models, Christiano et al. (2011) and Mao Takongmo (2017) both used the government spending multiplier as an indicator of the link between the government spending and the gross domestic product. In this paper, we use a causality measure.

Christiano et al. (2011) showed that, in a closed economy (i.e., when the exchange rate is not relevant), the government spending multiplier can be very large because in the ZLB period of such an economy, when the government increases spending, there is no crowding out effect through a nominal interest rate, as is usually the case in normal periods. ${ }^{5}$ The mechanism that led to a large government spending multiplier in Christiano et al. (2011) can be summarized as an increase in government spending leading to an increase in production, the marginal cost, and the usual expected inflation. This causes a decrease in the real interest rate $^{6}$ (because the nominal interest rate is bound [approximately constant] in ZLB periods). Households then consume more. ${ }^{7}$ The increase in household spending increases GDP, marginal costs, and expected inflation, leading to another decrease in the real interest rate; thus, the multiplier process continues. This leads to a large increase in the government spending multiplier. Christiano et al. (2011) showed that the government spending multiplier can be four. ${ }^{8}$

Mao Takongmo (2017) also provided more information about the link between government spending and the GDP in ZLB periods and in an open economy (i.e., when the exchange rate is taken into account). The author showed that, in an open economy, while increased government spending in the ZLB period increases the aggregate demand, it also leads to an appreciation of the real exchange rate, which reduces the aggregate demand, thereby leading to a lower government spending

\footnotetext{
${ }^{4}$ Mao Takongmo (2020) provides a theory and a quantitative description of DSGE models.

5 The crowding out effect is a situation in which we observe an increase in the real interest rate and a reduction of private investments due to the increase in government spending.

6 The real interest rate is approximately equal to the nominal interest rate minus the expected inflation.

7 Because lending does not provide large real interest.

8 i.e., an increase of $\$ 1$ of government spending leads to an increase of approximately $\$ 4$ of GDP.
} 
multiplier than what Christiano et al. (2011) presented. As presented in Table 3 of Mao Takongmo (2017), the government spending multipliers are larger in ZLB periods than in normal periods, when the economy is closed (i.e., the exchange rate is not relevant). Table 3 of Mao Takongmo (2017) also indicates that, in an open economy (i.e., when the exchange rate matters), even if the government spending multiplier is greater in ZLB than in normal periods, the difference is not as large as in a closed economy.

\section{Role Played by the Exchange Rate}

We saw that the causalities between government spending and GDP when the exchange rate is taken into account (conditional causality) is lower than the causality when the exchange rate is not taken into account (unconditional causality). This suggests that the exchange rate might be absorbing the link between government spending and gross domestic product. To see this, we estimate the causality between the exchange rate and government spending and the link between the exchange rate and GDP.

Panels $\mathrm{c}$ and $\mathrm{d}$ of Fig. 5 present the conditional causality measures between the exchange rate and gross domestic product in ZLB, conditional on government spending. Panels $\mathrm{c}$ and $\mathrm{d}$ of the figure show a direct causality between exchange rate and gross domestic product as well as vice versa, up to horizon 2 . Thus, any impact on exchange rate is likely to spread out into an impact on GDP and any impact of GDP is likely to spread out into an impact on the exchange rate.

Panels $a$ and $b$ of Fig. 5 present the causality measure between the exchange rate and government spending in ZLB, conditional on the gross domestic product. The figure shows that the exchange rate affects the government spending up to horizon 2 and government spending affects the exchange rate up to horizon 3. Once again, any impact on government spending will have an impact on the exchange rate, and any impact on the exchange rate will have an impact on government spending. The unconditional causality between government spending and the exchange rate is even very strong and persistent (see panels a and B of Fig. 6).

A plausible mechanism driving the results in this paper is the strong direct causality between government spending and the exchange rate. In other words, when a government increases spending, it affects only the real exchange (which represents the main real price of goods and services in an open economy). Increasing government spending does not significantly directly affect the GDP. It has to go through a multiplier process - in this case, the exchange rate. If the exchange rate did not significantly affect the GDP, we would observe a low direct causality between government spending and the exchange rate. The plausible picture is that increasing government spending only changes the real international price of goods and services (the real exchange rate) and does not significantly affect the production.

This fact is also visible in panels a and b of Fig. 6, which plot the unconditional causality between the exchange rate and government spending. These panels show a large and persistent unconditional causality measure between the exchange rate and government spending in the ZLB period. This result is consistent with the DSGE literature, which shows that an increase in government spending affects the real 

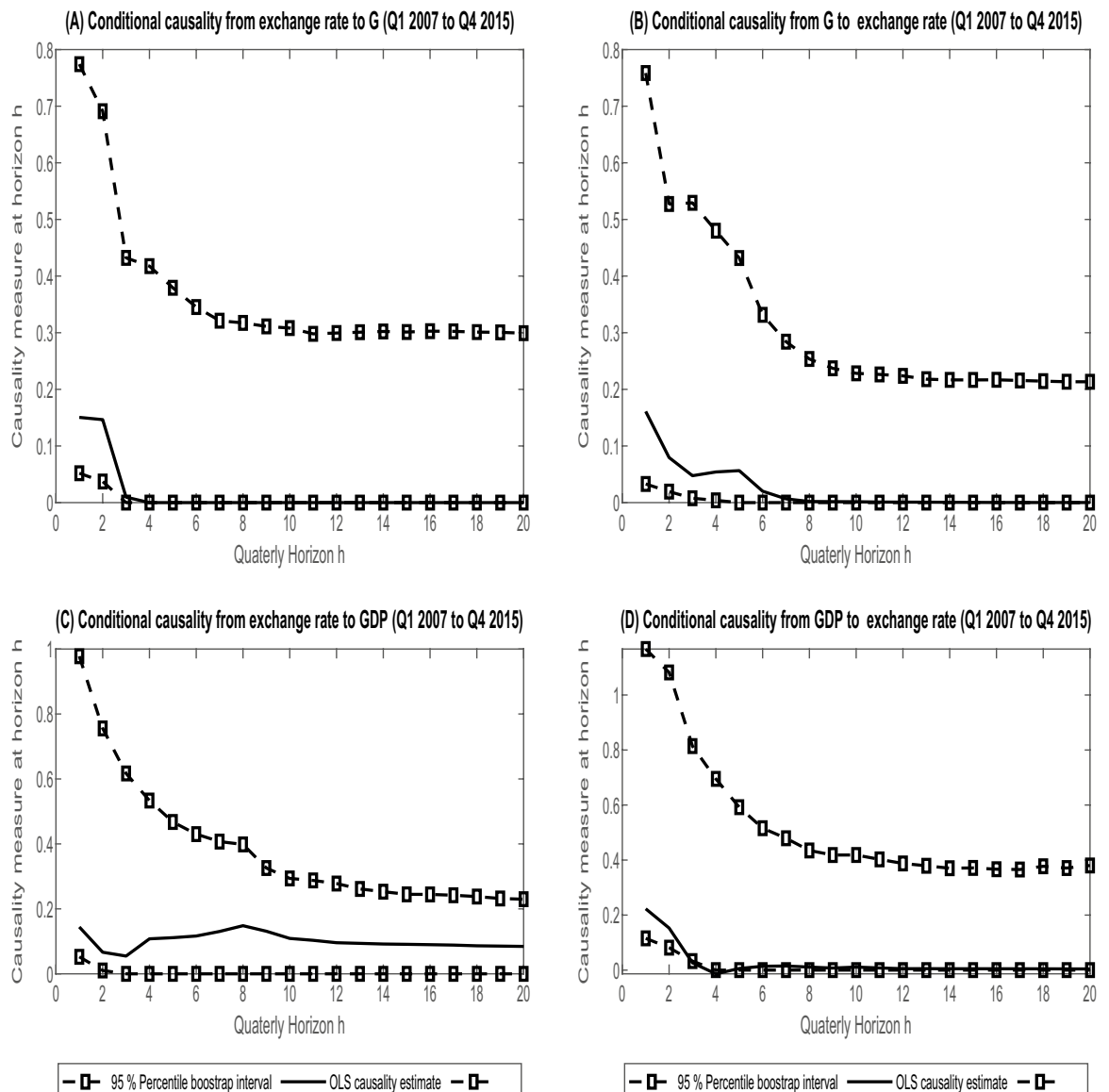

- $\mathbf{0}-95 \%$ Percentile boostrap interval $\longrightarrow$ OLS causality estimate $-\boldsymbol{D}$

$95 \%$ Percentile boostrap interval 0 OLS causality estimate $-\boldsymbol{0}-$

Fig. 5 Conditional causality measures between the exchange rate and government spending and between the exchange rate and GDP in the ZLB period (Q1 2007 to Q4 2015). Note: This figure presents the conditional causalities between the exchange rate and government spending, conditional on GDP (a, b). The figure also shows the causality measures between the exchange rate and GDP, conditional on government spending (c, d). Data used in the estimation process span from Q1 2007 to Q4 2015

exchange rate (the real international price of goods and services). Thus, this strong causality between government spending and the exchange rate absorbs the direct causality between government spending and the GDP.

\section{Conclusion}

The aim of this paper is to assess, for the United States, the Granger causality measure between government spending and real GDP and to compare the value obtained in ZLB to that obtained in normal periods. We used quarterly data from 1959Q1 to 2015Q4 for the United States. Variables used included the real GDP, government 

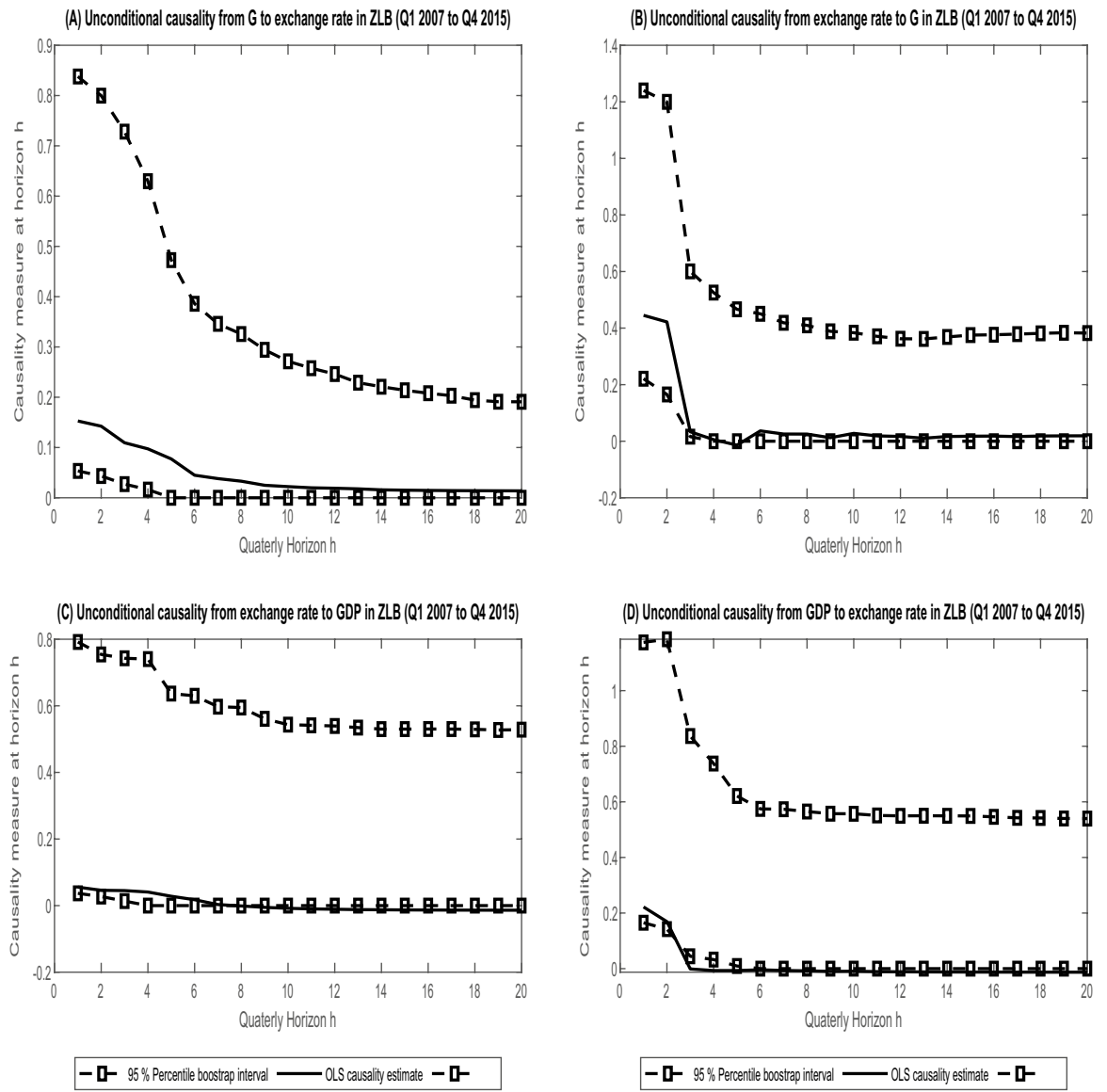

Fig. 6 Unconditional causality measures between the exchange rate and government spending and between the exchange rate and GDP in the ZLB period (Q1 2007 to Q4 2015). Note: This figure presents the unconditional causalities between the exchange rate and government spending and between the exchange rate and GDP in the ZLB period

spending, and the real exchange rate between the United States and Canada. Many researchers have used a theoretical model in a closed economy to show that the elasticity between government spending and the GDP might be very large in the ZLB period compared to normal periods. Meanwhile, in an open economy in general, other researchers have built theoretical models to show that the elasticity between government spending and the GDP in the ZLB period might not be very large. The same conflicting results are reported in the empirical literature that mostly used VARs, with different restrictions. This paper uses a different approach to measure the link between government spending and GDP. The new approach has the advantage of not relying on any restrictions, as is usually the case with VARs when researchers are identifying the government spending shock in order to provide an estimator that can be viewed as causal. Moreover, our approach is not related to the 
way the model is built, as is the case with DSGE types of models. In this paper, the Granger causality is used to compare the measure of causality for a normal period with the measure of causality obtained for ZLB periods. We emphasize the role played by the real exchange rate. Our results present evidence that, in ZLB, the Granger causality measure is stronger and more persistent if the exchange rate is not taken into account, but it becomes lower and does not last very long if the real exchange rate is taken into account.

Acknowledgements We wish to thank two anonymous referees, the associate editor and the editor for their valuable suggestions. We also thank Professor Jean-Marie Dufour for his useful discussions and comments. Earlier versions of this paper were presented at the University of Quebec at Montreal.

\section{References}

Ahmed, S. 1986. Temporary and permanent government spending in an open economy: Some evidence for the united kingdom. Journal of Monetary economics 17 (2): 197-224.

Auerbach, A.J., and Y. Gorodnichenko. 2012. Fiscal multipliers in recession and expansion. In Fiscal policy after the financial crisis, 63-98. University of Chicago Press.

Barro, R.J. 1991. Economic growth in a cross section of countries. The Quarterly Journal of Economics 106 (2): 407-443.

Chodorow-Reich, G. 2019. Geographic cross-sectional fiscal spending multipliers: What have we learned? American Economic Journal: Economic Policy 11 (2): 1-34.

Chow, G.C. 1960. Tests of equality between sets of coefficients in two linear regressions. Econometrica 28 (3): 591-605.

Christiano, L., M. Eichenbaum, and S. Rebelo. 2011. When is the government spending multiplier large? Journal of Political Economy 119 (1): 78-121.

Crafts, N., and T.C. Mills. 2013. Rearmament to the rescue? New estimates of the impact of "keynesian" policies in 1930s' britain. The Journal of Economic History 73 (4): 1077-1104.

Dufour, J.M., and E. Renault. 1998. Short run and long run causality in time series: Theory. Econometrica 66 (5): 1099-1125.

Dufour, J.M., and A. Taamouti. 2010. Short and long run causality measures: Theory and inference. Journal of Econometrics 154 (1): 42-58.

Fay, M.P., and M.A. Proschan. 2010. Wilcoxon-mann-whitney or t-test? On assumptions for hypothesis tests and multiple interpretations of decision rules. Statistics Surveys 4: 1.

Fölster, S., and M. Henrekson. 1999. Growth and the public sector: A critique of the critics. European Journal of Political Economy 15 (2): 337-358.

Geweke, J. 1982. Measurement of linear dependence and feedback between multiple time series. Journal of the American Statistical Association 77 (378): 304-313.

Gordon, R.J., and R. Krenn. 2010. The end of the great depression 1939-41: Policy contributions and fiscal multipliers (Tech. Rep.). National Bureau of Economic Research.

Granger, C.W. 1969. Investigating causal relations by econometric models and cross-spectral methods. Econometrica: Journal of the Econometric Society 5: 424-438.

Grier, K.B., and G. Tullock. 1989. An empirical analysis of cross-national economic growth, 1951-1980. Journal of Monetary Economics 24 (2): 259-276.

Hamilton, J.D. 1994. Time series analysis, vol. 2. Princeton: Princeton University Press.

Ilzetzki, E., E.G. Mendoza, and C.A. Végh. 2013. How big (small?) are fiscal multipliers? Journal of Monetary Economics 60 (2): 239-254.

Karras, G. 2012. Trade openness and the effectiveness of fiscal policy: Some empirical evidence. International Review of Economics 59 (3): 303-313.

Lee, J.W. 1995. Capital goods imports and long-run growth. Journal of Development Economics 48 (1): 91-110. 
Mao Takongmo, C.O. 2017. Government-spending multipliers and the zero lower bound in an open economy. Review of International Economics 25 (5): 1046-1077.

Mao Takongmo, C.O. 2020. DSGE models, detrending, and the method of moments. Bulletin of Economic Research. https://doi.org/10.1111/boer.12234.

McCloskey, D.N., and S.T. Ziliak. 1996. The standard error of regressions. Journal of Economic Literature 34 (1): 97-114.

McCracken, M.W., and S. Ng. 2016. Fred-md: A monthly database for macroeconomic research. Journal of Business \& Economic Statistics 34 (4): 574-589.

Mitchell, D.J., et al. 2005. The impact of government spending on economic growth. The Heritage Foundation 1813: 1-18.

Miyamoto, W., T.L. Nguyen, and D. Sergeyev. 2018. Government spending multipliers under the zero lower bound: Evidence from japan. American Economic Journal: Macroeconomics 10 (3): 247-77.

Miyamoto, W., T.L. Nguyen, and V. Sheremirov. 2019. The effects of government spending on real exchange rates: Evidence from military spending panel data. Journal of International Economics 116: 144-157.

Mundell, R.A. 1963. Capital mobility and stabilization policy under fixed and flexible exchange rates. Canadian Journal of Economics and Political Science/Revue canadienne de economiques et science politique 29 (4): 475-485.

Owyang, M.T., V.A. Ramey, and S. Zubairy. 2013. Are government spending multipliers greater during periods of slack? Evidence from twentieth-century historical data. American Economic Review 103 (3): 129-34.

Ramey, V.A., and S. Zubairy. 2018. Government spending multipliers in good times and in bad: Evidence from us historical data. Journal of Political Economy 126 (2): 850-901.

Ricci, L.A., G.M. Milesi-Ferretti, and J. Lee. 2013. Real exchange rates and fundamentals: A cross-country perspective. Journal of Money, Credit and Banking 45 (5): 845-865.

Stock, J.H., and M.W. Watson. 2012. Disentangling the channels of the 2007-09 recession. Brookings Papers on Economic Activity 1: 120-157.

Wiener, N. 1956. The theory of prediction. Modern Mathematics for Engineers 1: 125-139.

Wilcoxon, F. 1945. Individual comparisons by ranking methods. Biometrics Bulletin 1 (6): 80-83.

Woodford, M. 2011. Simple analytics of the government expenditure multiplier. American Economic Journal: Macroeconomics 3 (1): 1-35.

Zhang, H.J., J.M. Dufour, and J.W. Galbraith. 2016. Exchange rates and commodity prices: Measuring causality at multiple horizons. Journal of Empirical Finance 36: 100-120.

Zubairy, S. 2014. On fiscal multipliers: Estimates from a medium scale DSGE model. International Economic Review 55 (1): 169-195.

Publisher's Note Springer Nature remains neutral with regard to jurisdictional claims in published maps and institutional affiliations. 